\title{
Intussusception in Children: A Prospective Cohort Study
}

\section{ABSTRACT}

Introduction: Intussusception is one of the most frequent causes of bowel obstruction in infants and toddlers. Due to wide variety of clinical presentations and overlap with other abdominal conditions, the diagnosis of intussusception is often delayed. Delayed diagnosis and treatment leading to gangrene and perforation of the bowel increases the morbidity and mortality of this condition. Therefore, prompt diagnosis and treatment is warranted for better outcome.

Aim: To find out the possible aetiological factors, clinical presentation and treatment outcome of intussusception in children.

Materials and Methods: A prospective descriptive cohort study was conducted in the Department of General Surgery from October 2018 to November 2020, in which 30 patients with diagnosis of intussusception undergoing either hydrostatic reduction or open surgical intervention were enrolled. Age and sex were the independent variables while surgical outcome was the dependent variable assessed.

Results: Thirty patients (males $=17$ and females $=13$ ) of intussusception with mean age $10.8 \pm 19.12$ months were included in the study. In $83.33 \%$ patients, intussusception was idiopathic, while, pathological lead point was noted in $16.67 \%$ patients. Ileocolic $(76.67 \%)$ was the most common type of intussusception detected. A $70 \%$ patient's required open surgery while hydrostatic reduction carried out in $30 \%$ patients. No mortality was observed in this study.

Conclusion: The commonly affected age group was 7 to 12 months. Surgery is the mainstay of treatment while hydrostatic reduction is effective in few properly selected patients.

\section{INTRODUCTION}

Intussusception occurs when a portion of alimentary tract is telescoped into an adjacent segment [1]. First described by Paul Barbette of Amsterdam in 1674, most intussusceptions in children occur from 2 months to 2 years of age [2,3]. In children, more than $80 \%$ intussusceptions are ileocolic, beginning several centimetres proximal to the ileocaecal valve with their apex found in the ascending or transverse colon [2]. Incidence of intussusception is 1 to 4 per 1000 live births and has geographical variation [1]. Exact aetiology of intussusception cannot be determined in nearly $90 \%$ of cases and it is labeled as an idiopathic intussusception. The classical triad of Ombredanne seen in intussusception includes abdominal pain, abdominal lump and passage of "red currant jelly" stool. [4].

Diagnosis of intussusception is delayed as it mimics other acute abdominal conditions which increase morbidity and mortality. Therefore, prompt diagnosis and treatment are warranted for better outcome. In the literature, there is no consensus about the best procedure for non surgical reduction of intussusception. Singh AP et al., achieved $88 \%$ overall success rate for ultrasound guided pneumatic reduction in their study [5]. Xie $X$ et al., in their randomised trial, compared pneumatic and hydrostatic reduction for intussusception in paediatric patients and reported high success rate in hydrostatic reduction group [6]. Ultrasound guided hydrostatic reduction is recommended because there is no radiation exposure and ultrasonography is useful in both diagnosis as well as reduction $[7,8]$. Hence, present study was conducted with the aim to assess the clinical presentation, possible aetiological factors and treatment outcome in patients having intussusceptions. Intussusception is a paediatric condition,but as there is no dedicated paediatric surgery unit in our institute hence, this study is first of its kind conducted in General Surgery Department in the institute.

\section{MATERIALS AND METHODS}

This prospective descriptive cohort study was carried out in the Department of General Surgery of Dr. Vaishampayan Memorial
Government Medical College and Shri. Chhatrapati Shivaji Mahara Survopachar Rugnalaya tertiary care hospital, Solapur (Maharashtra), India from October 2018 to November 2020, after obtaining the approval of Institutional Ethical Committee dated 4/10/2018.

Thirty patients of intussusception were included out of which 17 were males and 13 were females. Informed consent was obtained from the parents or guardian of the children before enrolment in the study in prescribed proforma.

Inclusion criteria: Patients $\leq 12$ years, irrespective of sex, with radiological diagnosis of intussusception.

Exclusion criteria: Patients above 12 years of age, patients not willing for the treatment and discharged against medical advice were excluded from the study.

\section{Study Procedure}

On admission, the patients were examined thoroughly, and history was recorded from the parents or caretakers in prescribed proforma. Patients who presented with shock were immediately admitted to the surgical ward, adequately resuscitated and when they become haemodynamically stable they were shifted for radiological investigations. Weight was recorded in all patients for calculation of antibiotics dosages and fluid requirements. Necessary laboratory investigations were performed in all patients. Depending upon the clinical condition of patient they were subjected to either hydrostatic reduction or open surgery. Stable patients not showing signs of perforation peritonitis, shock or gangrene of bowel were subjected to hydrostatic reduction. For hydrostatic reduction, patient was shifted to ultrasonography suit after taking written informed consent of the parents and explaining possible complications related to the procedure. Operation theatre staff were also informed about the procedure and necessary preparations for open surgery was made to tackle the situation in case perforation occurs or the reduction fails. In supine position, appropriate sized foley's catheter (no. 18-24) was inserted in rectum of patient and bulb inflated with normal saline. Foley's catheter 
was connected to an enema can filled with 2 litres of normal saline and about 1 meter above the level of table. The normal saline flows into the rectum due to gravity. External force was not applied. Once the saline flow was started, the abdomen was scanned for signs of regression of intussusception. When the fluid flows freely through the ileocaecal valve into the terminal ileum and intussusception disappears, the procedure was considered successful.

After successful reduction, the fluid in the colon and rectum was drained out. Patient's vitals were monitored throughout the procedure. After successful reduction, patient was shifted to the ward for observation, if recurrence occurs in ward the same procedure was repeated once and, if failed, the patient was immediately subjected to open surgery. For open surgery, either right sided supra-umbilical transverse or vertical midline incision was used, depending upon the age of the patient. After laparotomy, depending upon the intraoperative findings, appropriate surgical procedure was performed. Depending upon intraoperative findings (the extent of intussusceptum into intussuscipiens), the intussusception was classified into various types [9]. The patient was shifted to paediatric Intensive Care Unit (ICU), if required, for continuous monitoring after consultation with anaesthetist. In postoperative period the patients were observed for possible complications and if developed, treated accordingly. After discharge, patients were followed-up for first three months.

\section{STATISTICAL ANALYSIS}

All the statistical analysis was carried out by Statistical Package for Social Sciences (SPSS) version 16.0. Tables and graphs were created with the help of Microsoft Word and Excel. Statistical method used was t-test. The $p$-value $<0.05$ was considered statistically significant.

\section{RESULTS}

Out of the total 30 patients studied, $56.67 \%$ were males and $43.33 \%$ were females. Majority of patients were in age group of 7 to 12 months [Table/Fig-1]. Vomiting and abdominal pain were the predominant symptoms noted in these patients. In $83.33 \%$ patients, intussusception was labelled as idiopathic as no exact aetiological factor was detected [Table/Fig-2]. Pathological lead points (mesenteric lymph nodes, Appendix etc.,) were noted in $16.67 \%$ patients [Table/ Fig-2-4]. The mean time interval between onset of symptoms and admission to hospital in our study was $31.6 \pm 15.28$ hours [Table/ Fig-5]. Laparotomy+manual reduction was the most common surgical procedure performed in open group $(n=17)$ [Table/Fig-6]. Seasonal variation was observed in our study with most cases observed in summer [Table/Fig-7]. Hospital stay was more in open surgery group and was statistically significant $(\mathrm{p}<0.05)$ [Table/Fig-8]. Classical triad of intussusception was present in $36.7 \%(n=11)$ of patients in our study. Surgical site infection was the most common complication noted in patients who had undergone open surgery [Table/Fig-9]. There were no complications noted in patients who had undergone hydrostatic reduction. Recurrence rate of $11.11 \%$ and $0 \%$ noted in hydrostatic reduction group and open surgery group, respectively [Table/Fig-10]. In present study, the rate of bowel resection was $13.33 \%(n=4)$. There was not a single case of death noted in our study.

\begin{tabular}{|c|c|c|c|}
\hline Age group (Months) & Number of patients & Percentage & Mean age (Months) \\
\hline $0-3$ & 9 & $30 \%$ & \multirow{8}{*}{$10.8 \pm 19.12$} \\
\hline $4-6$ & 6 & $20 \%$ & \\
\hline $7-12$ & 12 & $40 \%$ & \\
\hline $13-24$ & 1 & $3.3 \%$ & \\
\hline $25-37$ & 1 & $3.3 \%$ & \\
\hline 38- 48 & 0 & 0 & \\
\hline$>48$ & 1 & $3.3 \%$ & \\
\hline Total & 30 & $100 \%$ & \\
\hline
\end{tabular}

\begin{tabular}{|c|c|c|}
\hline Characteristics & $\begin{array}{l}\text { No. of patients } \\
(n=30)\end{array}$ & Percentage \\
\hline \multicolumn{3}{|l|}{ Gender } \\
\hline Male & 17 & $56.67 \%$ \\
\hline Female & 13 & $43.33 \%$ \\
\hline \multicolumn{3}{|l|}{ Clinical features } \\
\hline Vomiting & 27 & $90 \%$ \\
\hline Abdominal colic pain & 23 & $76.67 \%$ \\
\hline Rectal bleeding & 13 & $43.33 \%$ \\
\hline Abdominal mass & 16 & $53.33 \%$ \\
\hline Irritability & 11 & $36.67 \%$ \\
\hline Fever & 8 & $26.67 \%$ \\
\hline \multicolumn{3}{|l|}{ Type of treatment } \\
\hline Hydrostatic reduction & 9 & $30 \%$ \\
\hline Open surgery & 21 & $70 \%$ \\
\hline \multicolumn{3}{|l|}{ Types of intussusceptions [9] } \\
\hline Ileocolic & 23 & $76.67 \%$ \\
\hline Ileocaecal & 3 & $10 \%$ \\
\hline Ileoileal & 2 & $6.67 \%$ \\
\hline Ileo-caeco-colic & 1 & $3.33 \%$ \\
\hline Colocolic & 1 & $3.33 \%$ \\
\hline \multicolumn{3}{|l|}{ Aetiology } \\
\hline 1.Idiopathic & 25 & $83.33 \%$ \\
\hline 2.Pathological lead point & 5 & $16.67 \%$ \\
\hline a) Mesenteric Lymph nodes & 1 & $3.33 \%$ \\
\hline b) Meckel's diverticulum & 1 & $3.33 \%$ \\
\hline c) Hypertrophy of payer's patches & 2 & $6.67 \%$ \\
\hline d) Appendix & 1 & $3.33 \%$ \\
\hline
\end{tabular}
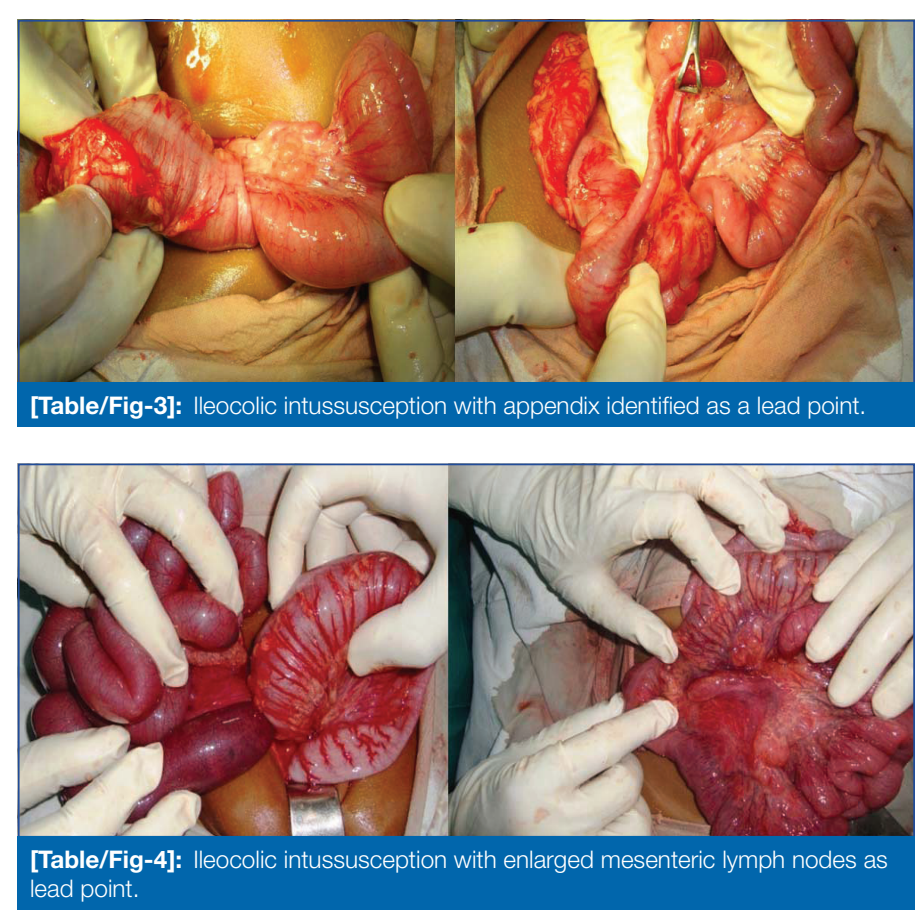

\begin{tabular}{|l|c|c|}
\hline Onset of symptoms- admission interval & Number of patients & Percentage \\
\hline Up to 12 hours & 5 & $16.67 \%$ \\
\hline 13-24 hours & 6 & $20 \%$ \\
\hline 25-36 hours & 2 & $6.67 \%$ \\
\hline 37-48 hours & 16 & $55.33 \%$ \\
\hline More than 48 hours & 1 & $3.33 \%$ \\
\hline Total & 30 & $100 \%$ \\
\hline [Table/Fig-5]: Time of presentation to hospital from the onset of symptoms.
\end{tabular}




\begin{tabular}{|l|c|c|}
\hline Procedures & Number of patients & Percentage \\
\hline Laparotomy+Manual reduction & 17 & $80.95 \%$ \\
\hline $\begin{array}{l}\text { Laparotomy+Bowel resection with primary } \\
\text { anastomosis }\end{array}$ & 3 & $14.28 \%$ \\
\hline Laparotomy+Bowel resection with stoma & 1 & $4.77 \%$ \\
\hline Total & 21 & $100 \%$ \\
\hline $\begin{array}{l}\text { [Table/Fig-6]: Distribution of patients according to surgical procedures in open } \\
\text { group. }\end{array}$
\end{tabular}

\begin{tabular}{|l|c|c|}
\hline Seasonal variation & Number of patients & Percentage \\
\hline Summer (Feb, March, April, May) & 18 & $60 \%$ \\
\hline Rainy season (June, July, August, Sept) & 7 & $23.33 \%$ \\
\hline Winter (Oct, Nov, Dec, Jan) & 5 & $16.67 \%$ \\
\hline Total & 30 & $100 \%$ \\
\hline
\end{tabular}

\begin{tabular}{|c|c|c|c|c|c|}
\hline \multirow[b]{2}{*}{ Treatment } & \multirow[b]{2}{*}{$\begin{array}{l}\text { Number of } \\
\text { patients }\end{array}$} & \multicolumn{2}{|c|}{ Hospital stay } & \multirow[b]{2}{*}{$\begin{array}{c}\text { Unpaired } \\
\text { t test }\end{array}$} & \multirow[b]{2}{*}{$p$-value } \\
\hline & & $\begin{array}{l}\text { Mean } \\
\text { days }\end{array}$ & $\begin{array}{c}\text { Standard } \\
\text { deviation (SD) }\end{array}$ & & \\
\hline $\begin{array}{l}\text { Hydrostatic } \\
\text { reduction }\end{array}$ & 9 & 4 & 1.11 & \multirow[t]{2}{*}{5.6} & \multirow[t]{2}{*}{0.000003} \\
\hline Open surgery & 21 & 10.14 & 3.09 & & \\
\hline
\end{tabular}

\begin{tabular}{|l|c|c|}
\hline Postoperative complications & Number of patients & Percentage \\
\hline Surgical site infection & 3 & $10 \%$ \\
\hline Wound dehiscence & 1 & $3.33 \%$ \\
\hline Incisional hernia & 1 & $3.33 \%$ \\
\hline
\end{tabular}

\begin{tabular}{|l|c|c|c|}
\hline $\begin{array}{l}\text { Type of surgical } \\
\text { procedure }\end{array}$ & $\begin{array}{c}\text { Total } \\
\text { patients }\end{array}$ & $\begin{array}{c}\text { Number of patients } \\
\text { with recurrence }\end{array}$ & Recurrence rate \\
\hline Hydrostatic reduction & 09 & 1 & $11.11 \%$ \\
\hline Surgical reduction & 21 & 0 & 0 \\
\hline
\end{tabular}

\section{DISCUSSION}

Intussusception is uncommon below three months of age and after three years of life and also the seasonal variations were observed in our study with the most number of cases observed in summer.

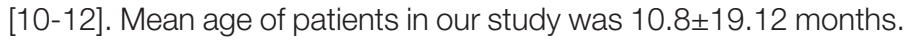
The mean age of patients in the national studies conducted by Chatterjee US et al., and Gupta M et al., studies were 11 months and 10 months respectively [13,14]. Mean age of patients in the international studies by Al-Bassam AA and Orfale N, Mensah $Y$ et al., were 11.5 months and 11.7 months, respectively $[15,16]$. These findings in both national and international studies are comparable with our study. Male were more commonly affected than females in our study with male to female ratio of 1.3:1. Similar trend of male preponderance is also documented in the other studies by Archibong AE et al., Chalya PL et al., Guo W et al., [17-19].

In the present study, vomiting and abdominal pain were reported in $90 \%$ and $76.6 \%$ of patients respectively. While rectal bleeding and abdominal lump were noted in $43.3 \%$ and $53.3 \%$ patients respectively. Similar clinical presentation of intussusception was also observed in study conducted by Crankson SJ et al., where vomiting and abdominal pain were present in $78 \%$ and $65 \%$ patients respectively, while rectal bleeding and abdominal mass were detected in $81 \%$ and $62 \%$ patients respectively [20]. In the study conducted by Chalya PL et al., Ul-Hassan MF et al., the classical triad of intussusception was noted in $42.5 \%$ and $50 \%$ of patients, respectively $[18,21]$. These observations indicated that classic triad of intussusception was not present in all patients but present in nearly half to $1 / 3^{\text {rd }}$ of patients. Therefore, this condition should be suspected in all children under the age of three years presenting with acute colicky abdominal pain without delaying further treatment.

The mean time interval between onset of symptoms and admission to hospital in our study was $31.6 \pm 15.28$ hours. In the studies, conducted by Xuan NT et al., and Fernandes EG et al., mean time interval was 24 hours [22,23]. Time interval is more in our study because majority of patients presented late to hospital. Because of poverty, people from the villages prefer to take treatment from local doctors where they find it cheap. They don't mind the lack of expertise of the doctor. When the clinical state of patient deteriorated, then such patients were referred to the tertiary care centre for specialist management. Most common type of intussusception noted in our study was ileocolic. Similar findings were also noted in various other national and international studies [3,19,24]. In majority of patients in our study the exact aetiology of intussusception was not determined and is labelled as idiopathic intussusception. Similar findings were also observed in other studies [13,15,16,25,26].

In present study, the rate of bowel resection was $13.33 \%(n=4)$. In the study conducted by Al-Bassam AA and Orfale $\mathrm{N}$ the rate of bowel resection was $16.6 \%$, while that in the Kuremu RT study the rate of bowel resection was 33\% [15,25]. Bowel was resected when it was found gangrenous. In case of gangrene of small bowel segmental resection, an end to end anastomosis was performed. In case of gangrene of caecum or ascending colon, we performed right hemicolectomy with ileotransverse anastomosis. Bowel resection rate in our study is less as compared to these studies, this may be because of small sample size in our study. Maximum number of cases of intussusception in our study were detected during summer season. Similar trend was observed in the study conducted by Das MK et al., [26]. This may be because of increased incidence of Upper Respiratory Tract Infections (URTI) and gastrointestinal infections during summer in India predisposing patients to intussusception.

\section{Limitation(s)}

About $40 \%$ of patients, in this study did not report for follow-up for specified period after discharge, because of which it was not possible for the authors to document long term complications in these patients. Small sample size is also limiting factor of this study.

\section{CONCLUSION(S)}

Intussusception is common in children below one year. Classic triad of symptoms is present in only $1 / 3^{\text {rd }}$ of cases, making the diagnosis a challenging task. Hydrostatic reduction is recommended in properly selected patients. It is safe and effective procedure with decreased hospital stay and free from morbidity associated with surgical treatment. Surgery is the ultimate solution for failed hydrostatic reduction cases with its own complications.

\section{REFERENCES}

[1] Wyllie R. lleus, Adhesions, Intussusception, and Closed Loop Obstruction: Digestive System. In: A Kliegman RM, Behrman RE, Jenson HB, Stanton BF editors. NELSON TEXTBOOK OF PEDIATRICS. $18^{\text {th }}$ ed. Philadelphia: SAUNDERS; 2008. Pp. 1568-71.

[2] Lander A. Principles of paediatric surgery In: Williams NS, O'Connell PR, McCaskie AW, editors. Bailey \& Love's SHORT PRACTICE of SURGERY, $27^{\text {th }} \mathrm{ed}$. Great Britain: CRC Press; 2018. Pp.118-138.

[3] Pandey A, Singh S, Wakhlu A, Rawat J. Delayed presentation of intussusception in children-a surgical audit. Annals of Paediatric Surgery. 2011;7(4):130-32.

[4] Del-Pozo G, Albillos JC, Tejedor D, Calero R, Rasero M, de-la-Calle U, et al. Intussusception in children: Current concepts in diagnosis and enema reduction. RadioGraphics. 1999;19(2):299-319.

[5] Singh AP, Tanger R, Mathur V, Gupta AK. Pneumatic reduction of intussusception in children. Saudi Surg J. 2017;5:21-25.

[6] Xie X, Wu Y, Wang Qi, Zhao Y, Chen G, Xiang Bo. A randomised trial of pneumatic reduction versus hydrostatic reduction for intussusception in paediatric patients. J Pediatr Surg. 2018;53(8):1464-68

[7] Peh WC, Khong PL, Lam C, Chan KL, Cheng W, Lam WW, et al. Reduction of intussusception in children using sonographic guidance. AJR Am J Roentgenol. 1999;173:985-88 
[8] Wood SK, Kim JS, Suh SJ, Paik TW, Choi SO. Childhood intussusception: USguided hydrostatic reduction. Radiology. 1992;182:77-80.

[9] Ein SH, Daneman A. Intussusception. In: A Grosfeld JL, O’Neill JA Jr, Coran AG, Fonkalsrud EW. etitors. Pediatric Surgery. $6^{\text {th }}$ ed. Pliladephia: MOSBY: 2006. Pp.1313-1324.

[10] Nowshad MA, Moshtaque A, Hafizur R. Management outcome of infancy and childhood intussusception in Rajshahi Medical College hospital- a prospective study. TAJ. 2009;22(1):59-63.

[11] Bode CO. Presentation and management outcome of childhood intussusception in Lagos: A prospective study. Afr J Paediatr Surg. 2008;(5):24-28.

[12] Ignacio RC, Fallat ME. Intussusception. In: Holcomb GW, Murphy JP, Ostlie DJ, editors. Ashcraft's PEDIATRIC SURGERY. Philadelphia: SAUNDERS; 2010. Pp. 508-16.

[13] Chatterjee US, Ghosh A, Basu AK, Mukhopadhyay PP. Intraoperative hydrostatic reduction of intussusception. J Indian Assoc Pediatr Surg. 2008;13(3):107-08.

[14] Gupta M, Kanojia R, Singha R, Tripathy JP, Mahajan A, Saxena A, et al. Intussusception rate among under-five-children before introduction of rotavirus vaccine in North India. Journal of Tropical Paediatrics. 2018;64(4):326-35.

[15] Al-Bassam AA, Orfale N. Intussusception in Infants and Children: A Review of 60 Cases. Ann Saudi Med. 1995;15(3):205-08.

[16] Mensah Y, Glover-Addy H, Etwire V, Appeadu-Menash W, Twum M. Ultrasound guided hydrostatic reduction of intussusception in children at Korle Bu Teaching Hospital: An initial experience. Ghana Med J. 2011;45(3):128-31.

[17] Archibong AE, Usoro IN, Ikpi E, Inyang AA. Paediatric intussusception in Calabar, Nigeria. East Afr Med J. 2001;78(1):19-21.
[18] Chalya PL, Kayange NM, Chandika AB. Childhood intussusceptions at a tertiary care hospital in northwestern Tanzania: A diagnostic and therapeutic challenge in resource-limited setting. Ital J Pediatr. 2014;40(1):28.

[19] Guo W, Hu Z, Tan Y, Sheng M, Wang J. Risk factors for recurrent intussusception in children: A retrospective cohort study. BMJ Open. 2017;7(11):01-06.

[20] Crankson SJ, Al-Rabeeah AA,Fischer JD, Al-Jadaan SA, Namshan MA. Idiopathic intussusception in infancy and childhood. Saudi Med J. 2003;24 Suppl:S18-20.

[21] Ul-Hassan MF, Mufti GN, Bhat NA, Baba AA, Bucch M, Wani SA, et al. Management of intussusception in the era of ultrasound-guided hydrostatic reduction: A 3-year experience from a tertiary care center. J Indian Assoc Pediatr Surg. 2020;25(2):71-75.

[22] Xuan NT, Son NH, Thien HH . Treatment outcome of acute intussusception in children under two years of age: A prospective cohort study. Cureus. 2020;12(4):01-12.

[23] Fernandes EG, Leshem E, Patel M, Flannery B, GuedesPellini AC, Veras MA, et al. Hospital-based surveillance of intussusception among infants. J Pediatr. (Rio J.) 2016;92(2):181-87

[24] Hasan OB, Arif T, Ibrahim M. A clinical study of paediatric patients with intussusceptions. International Journal of Scientific Research. 2015;4(6):418-19.

[25] Kuremu RT. Childhood intussusception at the Moi teaching and Referral Hospital Eldoret: Management challenges in a rural setting. East Afr Med J. 2004:81(9):443-46.

[26] Das MK, Arora NK, Gupta B, Sharan A, Kameswari K, Padmalatha P, et al. Intussusception in children aged less than two years in India: Retrospective surveillance at nineteen tertiary care hospitals. Vaccine. 2020;38(43):6849-57.

PARTICULARS OF CONTRIBUTORS:

1. Associate Professor, Department of General Surgery, Dr. Vaishampyan Memorial Government Medical College, Solapur, Maharashtra, India.

2. Resident, Department of General Surgery, Dr. Vaishampyan Memorial Government Medical College, Solapur, Maharashtra, India.

3. Resident, Department of General Surgery, Dr. Vaishampyan Memorial Government Medical College, Solapur, Maharashtra, India.

\section{NAME, ADDRESS, E-MAIL ID OF THE CORRESPONDING AUTHOR:}

Dr. Santoshkumar Nagnath Deshmukh,

Shree Sadgurukrupa, Plot No-A/3, South Part, Sonia Nagar, Old Vidi Gharkul,

Near Hira-Moti Tower, Solapur-413005, Maharashtra, India.

E-mail: santoshkumarndeshmukh@gmail.com

\section{AUTHOR DECLARATION}

- Financial or Other Competing Interests: None

- Was Ethics Committee Approval obtained for this study? Yes

- Was informed consent obtained from the subjects involved in the study? Yes

- For any images presented appropriate consent has been obtained from the subjects. Yes

\section{PLAGIARISM CHECKING METHODS: [Jain H t al.]}

- Plagiarism X-checker: Mar 16, 2021

- Manual Googling: Aug 26, 2021

- iThenticate Software: Sep 24, $2021(12 \%)$
ETYMOLOGY: Author Origin

Date of Submission: Mar 14, 2021

Date of Peer Review: Jun 21, 2021

Date of Acceptance: Aug 27, 2021

Date of Publishing: Jan 01, 2022 